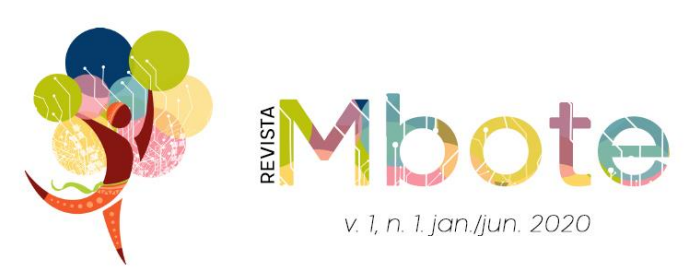

\title{
EJA NA PERSPECTIVA DA EDUCAÇÃO EM DIREITOS HUMANOS: IMPLICAÇÕES NO CONTEXTO SOCIAL
}

\author{
Adna Santos das NEVES ${ }^{1}$; Katia Siqueira de FREITAS ${ }^{2}$; \\ Antônio AMORIM ${ }^{3}$; Maria de Fátima Pessoa LEPIKSON ${ }^{4}$
}

\begin{abstract}
Resumo: $O$ texto discute o estigma e os prejuízos do analfabetismo para a população e para o país numa era de grande desenvolvimento e dependência da tecnologia. Entende a educação de jovens e adultos como um direito reconhecido desde pelo menos a Declaração Universal dos Direitos Humanos de 1948. Faz referências às políticas e legislações nacionais sobre educação. Pontua que o analfabetismo de jovens e adultos torna visível a desigualdade no Brasil. Comenta que $o$ ingresso na escola e a permanência bem sucedida é um direito em qualquer fase da vida. Advoga que educação é um direito ao longo de toda a vida e que além da alfabetização os professores devem enfatizar Educação em Direitos Humanos com enfoque interdisciplinar.
\end{abstract}

Palavras-chave: Educação de jovens e adultos. Direitos humanos. Alfabetização.

\section{EJA IN THE PERSPECTIVE OF HUMAN RIGHTS EDUCATION: IMPLICATIONS IN THE SOCIAL CONTEXT}

\begin{abstract}
The text discusses the stigma and damage of illiteracy to the population and the country in an era of great development and dependence on technology. It understands youth and adult education as a right recognized since at least the 1948 Universal Declaration of Human Rights. It makes reference to national policies and legislation on education. It points out that youth and adult illiteracy makes inequality visible in Brazil. He comments that entering school and staying successfully is a right at any stage of life. Advocates that education is a right throughout life and that in addition to literacy, teachers should emphasize Education in Human Rights with an interdisciplinary approach.
\end{abstract}

Keywords: Youth and adult education. Human rights. Literacy.

\section{INTRODUÇÃO}

Este artigo fomenta um diálogo em torno de um tema recorrente: a Educação de Jovens e Adultos (EJA) na perspectiva dos direitos humanos. Discute o estigma do analfabetismo e suas consequências para a vida de pessoas que se encontram

\footnotetext{
${ }^{1}$ Professora do Ensino Fundamental I. Gestora de Educação de Jovens e Adultos. Mestra e Doutoranda em Políticas Sociais e Cidadania pela Universidade Católica do Salvador (UCSAL). E-mail: nevesadna@yahoo.com.br

${ }^{2}$ Doutora e Pós-doutora pela The Pennsylvania State University, em Administração da Educação, Professora pesquisadora, Universidade Católica do Salvador (UCSAL). Líder do Grupo de Pesquisa Gestão e Avaliação de Políticas e Projetos Sociais. E-mail: sfkatia@gmail.com / http://orcid.org/0000-0003-0984-814X

${ }^{3}$ Pós-Doutorado em Difusão do Conhecimento pela Universidade Federal da Bahia (UFBA). Doutorado em Psicologia pela Universidade de Barcelona - Espanha. Professor Pleno da Universidade do Estado da Bahia (UNEB). Membro da Academia Baiana de Educação e Presidente da REDE Internacional de Pesquisa Colaborativa que congrega mais de 20 Grupos de Pesquisa. E-mail: antonioamorim52@gmail.com / https://orcid.org/0000-0003-3236-9139

4 Professora pesquisadora da Universidade Católica de Salvador (UCSAL) - Programa de Políticas Sociais e Cidadania. Doutorado em Educação pela Universidade Federal da Bahia (UFBA), Mestrado em Educação pela Universidade Federal de Santa Catarina (UFSC); Especialização em Metodologia do Ensino Superior; Graduada em Serviço Social pela UCSAL; Líder do Grupo de Pesquisa Questão Social, Estado e Sociedade Civil; Membro do Grupo de Pesquisa Políticas Públicas e Gestão Escolar. E-mail: lepikson@ucsal.br / https://orcid.org/0000-0002-4952-8768
} 
naquela condição. A gravidade dessa situação aumenta na contemporaneidade, com o advento de novas e cada vez mais complexas tecnologias a partir do incessante desenvolvimento científico e tecnológico. A educação e a escolarização são direitos sociais básicos para vida das pessoas durante todas as fases da vida humana e, como tal, estão sempre presentes nos debates e discussões que circundam os meios sociais, político e acadêmico.

A condição de iletrado interfere negativamente na vida pública e privada e no contexto social mais amplo. Limita o alcance ao trabalho qualificado e a afluência econômica. Impede a atuação participativa efetiva frente às questões sociais, quer sejam políticas, econômicas ou educacionais, pois a sociedade é plena de preconceitos contra os que não frequentaram a escola e contra os que a frequentaram e não obtiveram sucesso educacional. A pessoa iletrada e despreparada academicamente, no Brasil, assim como em outros países, vive num contexto social amplamente excludente e sofre duras consequências dessa exclusão preconceituosa.

A Declaração Universal dos Direitos Humanos ${ }^{1}$, de 1948, proclama igualdade de direitos para todos e realça o direito à instrução. O seu artigo XXVI afirma que:

Artigo XXVI 1. Todo ser humano tem direito à instrução. A instrução será gratuita, pelo menos nos graus elementares e fundamentais. A instrução elementar será obrigatória. A instrução técnico-profissional será acessível a todos, bem como a instrução superior, está baseada no mérito.

Desde então já se passaram 72 anos e "a igualdade de direito" continua como retorica. O avanço foi parcial, sobretudo para as camadas mais pobres da população do Brasil e de outros países emergentes.

Apenas gradativamente, a legislação brasileira incorporou atenção à educação, contudo até o momento ainda não conseguiu cumprir na íntegra o proclamado, especialmente com relação à qualidade da educação e dos serviços educacionais

\footnotetext{
${ }^{1}$ Disponível em: http://www.onu.org.br/img/2014/09/DUDH.pdf. Acesso em: 29/03/2017, às 20 40.
} 
como um todo. Dados do Instituto Brasileiro de Geografia e Estatística (IBGE) e da Organização das Nações Unidas para a Educação, a Ciência e Cultura (UNESCO) indicam que o Brasil, em 2015, era o oitavo país em número de analfabetos adultos no mundo, atingindo cerca de $13 \mathrm{mil}^{2}$. Cerca de $8 \%$ da população com 15 anos ou mais era analfabeta em $2015^{3}$. Como enfrentar e resolver essa situação incompatível com a modernidade, tem sido o questionamento de muitos educadores.

Estudos recentes apontam a importância de implementar medidas emergenciais para mudar esse panorama, caso contrário a tendência é que esse quantitativo aumente, contribuído para que o Brasil permaneça no rol de países com baixa qualidade educacional e com trabalhadores que não acompanham a realidade laboral. Analfabetismo e sistema educacional ineficiente interferem negativamente em toda estrutura social, política e econômica.

Erradicar o analfabetismo é a diretriz número 1 do Plano Nacional de Educação - Lei 13.005 de 2014 com vigência até $2024^{4}$. Cerca de seis depois de sua publicação, o Brasil continua com grande contingente de jovens e adultos que não tiveram oportunidade e/ou acesso a estudos que mudassem sua condição de analfabeto. Para que diretrizes, metas, ações e programas se concretizem efetivamente, é requerido a adoção de políticas concretas, planejadas, bem definidas e implementadas.

Dentre os elementos que compõem a manta de problemas constituintes da EJA na contemporaneidade, estão a ineficiência do sistema educacional para a preparação do conjunto de jovens, adultos e idosos e o distanciamento do mercado de trabalho e das famílias dos estudantes e dos potencias estudantes.

\footnotetext{
2 Disponível em: http://www.onu.org.br/index.php?s=alfabetiza\%C3\%A7\%C3\%A30\&x=0\&y=0. Acessado em: 29/03/2017, às $20 \mathrm{~h} 45$.

${ }^{3}$ Disponível em: http://brasilemsintese.ibge.gov.br/educacao/taxa-de-analfabetismo-das-pessoas-de15-anos-ou-mais.html. Acessado em: 29/03/2017, às 20 h50.

${ }^{4}$ Disponível em: http://www.observatoriodopne.org.br/uploads/reference/file/439/documentoreferencia.pdf. Acessado em: 29/03/2017, às 21h15.
} 
As constantes mudanças em todos os setores da vida humana e a internacionalização que ora se configuram nas esferas socioeconômicas, cultural, política e educacional geram novos e numerosos desafios e impactam na vida da população. Contudo, também apontam algumas possibilidades frente aos atuais problemas. Para tal, as sociedades e os poderes constituídos devem cumprir com a responsabilidade de atender a todos igualmente para que usufruam o direito à educação de qualidade para todos durante toda a vida. Negar a educação de qualidade é negar o direito a uma vida digna e à participação ativa no mercado de trabalho mais sofisticado intelectualmente; é promover a exclusão dos jovens, adultos e idosos e mantê-los à margem dos caminhos produtivos e de uma saúde saudável física e psicologicamente.

Neste contexto, estão os jovens, adultos e idosos analfabetos, semianalfabetos e analfabetos funcionais que compõem a população em potencial de alunos da EJA. Esses ao voltarem para a escola trazem grandes esperanças de superar seus limites, ganhar promoções no trabalho e serem absorvidos pelo mundo do trabalho formal. Esse mundo no qual pouca ou nenhuma possibilidade fica acessível a aqueles que não tiveram direito ao ensino básico de qualidade, considerado como instrumental mínimo para o exercício da cidadania plena e para o reconhecimento da sociedade e o alcance de melhor posição funcional no mercado de trabalho, outros.

A Lei de Diretrizes e Bases da Educação Nacional- LDB no 9394/96- estabelece no artigo 2 que a educação "tem por finalidade o pleno desenvolvimento do educando, seu preparo para o exercício da cidadania e sua qualificação para o trabalho" 5 . Contudo, o ensino básico é eivado de práticas educativas que não atendem aos anseios dos alunos quer sejam jovens, adultos ou idosos. Esses, em geral, são trabalhadores engajados em subempregos ou desempregados, marcados pela desigualdade social, que depositam muitas esperanças de sucesso na escolarização, que não é adequado às suas peculiaridades. As experiencias

\footnotetext{
${ }^{5}$ Disponível em: https://www2.senado.leg.br/bdsf/bitstream/handle/id/70320/65.pdf? sequence=3. Acessado em: 29/03/2017, às $23 \mathrm{~h} 30$.
} 
escolares frustradas dificultam o sucesso da aprendizagem escolar e contribuem para que abandonem os estudos.

Dando legitimidade à educação de qualidade aos jovens, adultos e idosos, Freitas (2009, p.188) advoga a gestão participativa e enfatiza que:

\footnotetext{
À proporção em que a educação nacional se institucionaliza como democrática e participativa, organiza seu sistema de ensino e as instituições educacionais, mais aumenta a necessidade de programas, estudos, pesquisas e experiências sobre a melhor forma de geri-las sob o marco da gestão democrata participativa.
}

A gestão escolar e o corpo docente juntos desempenham papel importantíssimo na elaboração de atividades adequadas às peculiaridades do corpo discente e à orientação da comunidade escolar e local. Podem inserir no currículo entrevistas e visitas à empresas, jornais, secretaria de educação, rádio, televisão, outros. Assim como, ao trabalhar a escrita podem treinar a elaboração de cartas de apresentação, de curriculum vitae, outros. Ao trabalhar a fala, podem simular entrevistas de emprego, e assim por diante. A leitura pode usar bulas de remédios, guias de instruções de como usar aparelhos domésticos ou de uso nas fábricas e no comercio.

\section{DESIGUALDADES SOCIO EDUCACIONAL E DIREITOS}

Os maiores problemas de países emergentes como o Brasil são as crescentes desigualdades sociais e educacionais. Há diferenças em quase todos os aspectos da educação, como por exemplo: qualidade gestora e pedagógica, acesso e permanência especialmente nos níveis mais altos de escolaridade, estrutura física das escolas, matérias escolares, merendas oferecidas, assim por diante.

Nesse cenário de oportunidades desiguais é que se configura a EJA como esperança daqueles que não tiveram oportunidade e/ou acesso de escolarização na "idade apropriada" conforme prevista em lei. Sendo a educação de qualidade um dever do estado e um direito de todo cidadão brasileiro, em toda e qualquer idade, concordamos com a crítica a expressão "idade apropriada" e reafirmamos que toda 
idade é apropriada para os cidadãos terem acesso à educação de acordo com a necessidade e interesse de cada um.

A EJA na perspectiva dos direitos humanos ajuda na construção de caminhos e possibilidades de inclusão educacional de toda a população durante toda a vida. Essa premissa corrobora com a efetivação de direitos, socioeconômico e laboral, favorecendo a participação nas políticas sociais. A inclusão, seja em qual instância for, se concretiza com a efetiva participação dos indivíduos na luta por direitos já consubstanciados e por novos que poderão ser construídos mediante educação que empodera e ajuda na conquista de novos direitos e oportunidades.

A inclusão educacional ocorre através de políticas, professores e currículo que atendam as especificidades dos diversos grupos sociais, quer sejam eles portadores de necessidades educativas especiais, quer estejam em situação de risco, de analfabetismo, desassistidos pela família e/ou pela sociedade, quer estejam em privação de liberdade, ou reclusos em hospitais, ou em regiões remotas e rurais do país ou mesmo no exterior e originários dos diferentes espaços sócio culturais. A esses grupos anexamos os imigrantes que com o cenário político atual encontram abrigo no Brasil, como exemplo temos os venezuelanos, e muitos outros povos que fogem das lutas e guerras que ocorrem na atualidade em seus países.

Independentemente de serem crianças, adolescentes, jovens, adultos ou idosos, todo e qualquer ser humano precisa e deve ser abraçado por oportunidades continuas de educação e aprimoramento. Pois, a aprendizagem é um processo que ocorre ao longo de toda a vida humana de diversas maneiras e alarga as oportunidades dos cidadãos de inserção e participação social. Educação contribui para a própria saúde física e psicológica de toda a família e do coletivo; aspectos que nos tornam mais humanos e colaboradores. O capital cultural formado na escola, conforme definido por Pierre Bourdieu, é determinante para o posicionamento do cidadão na sociedade.

\footnotetext{
${ }^{6}$ Disponível em: http://educarparacrescer.abril.com.br/aprendizagem/pierre-bourdieu-307908.shtml. Acessado em: 27/03/2017, às 20h00.
} 
Conforme Torres (2001, p.20), a educação básica é um espaço para ser ocupado por todos e deve atender às

[...] necessidades básicas de aprendizagem (NEBA) de crianças, jovens e adultos. As (NEBAs), por sua vez, eram definidas como aqueles conhecimentos teóricos e práticos, destrezas, valores e atitudes que, em cada caso e em cada circunstancias e momento concreto, tornam-se indispensáveis para que as pessoas possam encarar suas necessidades básicas.

As necessidades educacionais básicas atendidas ajudam a formação do capital cultural e a inserção social dos indivíduos de forma ativa, consciente de seus direitos e deveres. Elevam a qualidade de vida e colaboram com o processo de emancipação sociopolítica.

O cenário atual da EJA é de um ensino precário, com parte dos profissionais despreparados e pouca oportunidade de atualização, com currículo que raramente leva em conta o contexto sócio - histórico e cultural dos participantes, que, em geral, têm uma trajetória marcada pelo fracasso educacional, pela evasão e repetência; essas instancias minam a qualidade de vida e propiciam uma sociedade desigual e excludente como a que vivemos.

\section{PERMANÊNCIA E SUCESSO ESCOLAR}

É preciso lembrar as palavras de Ângela Antunes, Diretora Pedagógica do Instituto Paulo Freire, e de Carlos Rodrigues Brandão, Professor Colaborador da Universidade Estadual de Campinas e da Universidade Federal de Uberlândia, ao escreverem a apresentação do livro de Moacir Gadotti intitulado "Por uma política nacional de Educação popular de jovens e adultos" de 2014, quando afirmam que:

Os analfabetos não dispõem de um sindicato que os represente. Eles não têm porta-voz. Eles necessitam do empenho, da solidariedade e do compromisso dos que foram alfabetizados e estão hoje situados 
dentro e fora de instituições de poder do Estado ${ }^{7}$. (ANTUNES; BRANDÃO, 2014, p. 6).

A EJA atualmente emerge como uma das poucas oportunidades de organização política, acesso e permanência com sucesso nas escolas daqueles que desejam retornar as atividades de estudo após retirar-se da escola por algum tempo e estar em idade considerada inapropriada para frequentá-la durante o dia. Porém, mesmo essa oportunidade de estudo esbarra na pouca pertinência do ensino ministrado e convive com investimentos insatisfatórios. Além do mais, em Salvador, nos últimos anos, tem havido redução do número de escolas que oferecem educação de jovens e adultos.

A Lei de Diretrizes e Bases da Educação Nacional, no 9.394 de 20 de dezembro de 1996 (LDB), coloca em evidencia os direitos educativos dos jovens e adultos ao ensino, respeitando suas necessidades e condições de aprendizagem, incluindo a preparação para o exercício da cidadania e qualificação para o trabalho; estabelecendo as responsabilidades dos entes federados na identificação e mobilização de demandas emergentes ao ensino de jovens e adultos, com a garantia ao acesso e a permanência destes estudantes até o final do processo de escolarização.

A LDB (L. 9394/96) prevê atendimento aos jovens e aos adultos que não tiveram acesso ou não deram continuidade aos estudos na idade "apropriada" no ensino regular conforme já referido anteriormente. Contudo, até o momento é possível afirmar que o definido por meio desta lei não se configura enquanto realidade vivenciada pela EJA. Atualmente, a simples matricula dos estudantes na EJA não garante a sua permanência bem-sucedida no mundo escolar até completar o ciclo da escolarização básica. Essa realidade fomenta o alto índice de evasão e repetência nesta modalidade de ensino conforme pode ser observado em todo o Brasil. Tais questões estão relacionadas a fatores de diversas naturezas, quer sejam estrutural, social, econômica, ou cultural. Tais fatores prejudicam a qualidade do

\footnotetext{
7 Disponível em: http://www.moderna.com.br/lumis/portal/file/fileDownload.jsp?fileld=8A8A8A8246FB74BF0146FC10A 8A14E0E. Acessado em: 27/03/2017, às 16h.
} 
ensino ministrado e não ajudam a dirimir as dificuldades vivenciadas pelos estudantes. Outra variável que dificulta o sucesso escolar está relacionada ao fato de ser lugar comum a atuação de profissionais, tanto professores quanto gestores, com a formação voltada para crianças e jovens que aprendem a lidar com o adulto $e$ o idoso no próprio exercício do seu trabalho. Há ainda outros elementos que impactam negativamente no desempenho desses alunos, como a estrutura curricular inadequada ao público alvo a que se destina, tanto quanto a estrutura física precária. Fatores que acabam contribuído para a configuração do atual cenário da EJA no Brasil. Com muita propriedade Freitas (2016, p. 162 apud SILVA; COSTA; LIMA, 2016), comenta que:

Quando a qualidade da educação é deficitária aumenta a probabilidade de evasão, desistência, abandono total ou temporário dos que não conseguem acompanhar e vencer os desafios postos pelos sistemas educacionais. Esses engrossarão as estatísticas relativas a jovens e adultos que não persistiram com os estudos na "idade considerada oficialmente própria", mas que, muito provavelmente, retornarão ao sistema educacional por necessidades e circunstancias de vida e de trabalho.

Este é cenário vem se perpetuando. Boa parte dos estudantes acaba desistido de frequentar a escola por questões familiares e sócio econômicas bem como questões referentes a estrutura funcional desta modalidade de ensino que pouco atende às especificidades do estudante trabalhador seja ele jovem, adulto ou idoso, pai, mãe e avos. Há pessoas que trazem enquanto motivações a necessidade de trabalhar para ajudar no sustento da família. Mas, as dificuldades de aprendizagem, dificuldades outras enfrentadas por não ter com quem deixar os filhos para frequentar as aulas, cansaço depois de um dia de trabalho intenso, trânsito engarrafado na volta do trabalho, são alguns dos empecilhos os levam a desistir. Por vezes, problemas de ordem familiar (cuidar dos filhos ou de familiares com dependência física), educacional e socioeconômica fazem os estudantes não dar continuidade aos estudos. Outras são relativas à necessidade de se manter no emprego, assim por diante.

Atualmente, neste ano de 2020, a pandemia da COVID 19 - Coronavirus - é um fator a mais que tem dificultado a continuidade dos estudos dessa população de 
jovens e adultos devido ao agravamento da limitação financeira e da prevenção à contaminação. Nem todos têm bons celulares, computadores e sistema de internet que thes permita participar de teleaulas a partir de suas casas. Os sistemas de ensino têm buscado formas alternativas para oferecer aulas, mas até o momento inda buscam soluções estratégicas que tragam menos prejuízo à aprendizagem. 0 município de Salvador tem feito uso de material impresso, de grupos de discussão no WhatsApp, Zoom, como possibilidades para que os alunos continuem.

Mas, infalivelmente a necessidade de trabalhar, aprender a ler e escrever para usufruir dos benefícios da sociedade letrada se impõe e se sobrepõe ao seu cotidiano. A busca pela colocação no mercado de trabalho depende grandemente do sucesso na escola. Para responder às novas demandas apresentadas pela sociedade atual que exige indivíduos cada vez mais letrados e com compreensão crítica do mundo em que vivem, retomam a escola apesar das dificuldades e nela não encontram a compreensão de todas as dimensões do estágio e do processo em que se encontram.

A essa altura da vida, os interesses são múltiplos e variados. Almejam: resolver ou esquecer problema; ler o letreiro dos ônibus, jornal, revistas e livros; poder ajudar aos que necessitam; ensinar aos filhos ou neto; frequentar uma instituição escolar idealizada nos sonhos; socializa; adquirir informações para se tornarem pessoa conhecedoras dos seus direitos; usar eletrônicos; usufruir da internet; conseguir uma promoção; concluir os estudos; entrar para uma faculdade; saber operar uma calculadora e uma caixa eletrônico; constituir senhas para os cartões de banco. Esses são alguns dos interesses que precisam a ser considerados pelos planejadores e executores das políticas e ações relativas a EJA na atualidade.

Essa modalidade de ensino agrega jovens, adultos e idosos com uma faixa etária entre 15 e 80 anos ou mais, em sua maioria do sexo feminino, negros e pobres. Ou estão desempregados, ou exercem o trabalho formal, informal. Os tipos de trabalhos mais comuns são: empregadas domésticas, diaristas, pedreiros, donas de casa, vendedores, ambulantes. Alguns destes estudantes possuem déficit cognitivo, por 
vezes declarado e reconhecido pela família. Trazem vivências anteriores de fracasso e exclusão que contribuem para que carregarem o peso de uma autoimagem negativa. Muito embora, consigam manter muita vontade de aprender e de ver 0 mundo de uma maneira otimista, com esperança de futuro melhor.

Freire (2005, p. 43 e 44) faz uma reflexão sobre a necessidade por uma nova sociedade, que entenda o ser humano como sujeito de posse de si mesmo e de sua história de vida. Propõe que os países emergentes construam uma educação que seja uma força de mudança e libertação.

\section{O ESTIGMA DO ANALFABETISMO NO CONTEXTO SOCIAL}

O relatório divulgado no dia 20/01/2014, pela Organização das Nações Unidas para a Educação, a Ciência e a Cultura (UNESCO) apontam que o Brasil aparece em $8^{\circ}$ lugar entre os países com maior número de analfabetos adultos. Ao todo, o estudo avaliou a situação de 150 países. De acordo com a Pesquisa Nacional por Amostra de Domicílios (Pnad), feita pelo Instituto Brasileiro de Geografia e Estatística (IBGE) em 2012 e divulgada em setembro de 2013, a taxa de analfabetismo de pessoas de 15 anos ou mais foi estimada em $8,7 \%$, o que corresponde a 13,2 milhões de analfabetos no país ${ }^{8}$.

A causa do analfabetismo no Brasil entre outros fatores, segundo Galvão e Di Pierro (2007, p. 16), seria decorrente de fatores como "o trabalho precoce na lavoura, as dificuldades de acesso ou a ausência de escolas na zona rural". Com efeito, grande parte dos estudantes da EJA são remanescentes do êxodo rural. Deixaram suas cidades natal em busca de oportunidades de emprego nas cidades grandes, tentando melhorar as condições econômicas. Chegando à cidade esta parcela da população acaba recebendo baixa remuneração, exercendo funções como de limpeza, empregos em residências e pedreiro, dentre outras que não exigem ler e escrever com competência. Todavia, com as mudanças da configuração social e o

8 Disponível em: http://g1.globo.com/educacao/noticia/2014/01/brasil-e-o-8-pais-com-maisanalfabetos-adultos-diz-unesco.html. Acessado em: 26/03/2017, às $15 \mathrm{~h}$. 
uso das tecnologias em todos os tipos de serviços "Não saber ler e escrever é, como outras marcas distintivas da pobreza, um símbolo da condição de subalternidade", afirmam Mello e Gomes (1992, p. 21, apud GALVÃO; DI PIERRO, 2007, p.18). É um símbolo de desemprego, pois mesmo o serviço doméstico já requer que os candidatos sejam capazes de ler e escrever para que possam anotar recados, fazer compras e pagamentos, usar cartões de crédito e assumir outras responsabilidades. O serviço doméstico está inserido no contexto tecnológico de muitos eletrodomésticos e robores que limpam o chão da casa e vidraças, sendo preciso saber ler as instruções para operá-los sem danificá-los e com segurança.

Com relação a migração para a cidade, Galvão e Di Pierro (2007, p.17) comentam com propriedade que a maioria vem:

[...] em busca de melhores condições de vida e trabalho, no entanto, tiveram que enfrentar com mais freqüência situações de preconceito e responder a desafios de novos contextos, em que os usos da leitura e da escrita são mais difundidos, permeando a vida cotidiana.

A dura realidade dos que não leem, não escrevem, nem fazem, pelo menos, contas básicas em uma sociedade de letrados e de usuários das tecnologias, é cruel, pois ficam excluídos e a margem da sociedade. Saber ler, escrever e contar constituem competências básicas e condição mínima para a inclusão social e, consequente, entrada no mercado de trabalho. Indivíduos que não estejam devidamente alfabetizados e letrados são estigmatizados pela incapacidade de atender às demandas da modernidade tecnológica globalizada. Os jovens, adultos e idosos analfabetos são marcados pelo não reconhecimento de suas potencialidades, reforçando o sentimento de inferioridade, exclusão e marginalidade. A sociedade, em vez de exercer o que diz a legislação educacional, anula a individualidade e determina o modelo sócio político e econômico que interessa para manter o poder da classe dominante (a minoria), em detrimento da classe dominada, constituída pela grande maioria da população.

Em conformidade, com Di Pierro e Galvão, (2007, p.24), os sucessivos constrangimentos e experiências de discriminação levam à corrosão da autoestima 
dos indivíduos, que acabam assumindo a subalternidade e assimilando ao próprio discurso as metáforas depreciativas formuladas pelos letradas e difundidas pelos meios de comunicação. As mais recorrentes são aquelas que identificam o analfabetismo à "escuridão", à "cegueira"; o analfabeto ao "cego", e a alfabetização à "retirada da venda dos olhos" e a saída das "trevas da ignorância".

Segundo Goffman (2004), o indivíduo estigmatizado é um ser desviante, por estar fora da norma social e estar desacreditado, devido ao atributo de descrédito criado pelo meio social. $O$ iletrado recebe uma marca social negativa que faz com que pessoas que não se encontram nessas condições se distanciem por considerá-lo inferior. $\mathrm{O}$ analfabeto tende a ficar isolado, excluído e se sente incapaz socialmente.

Desta forma a democratização da educação só deixará de ser mera utopia a partir da efetivação das demais políticas: sociais, culturais, educacionais e econômicas, permitindo efetiva participação social da parcela excluída da sociedade por carregarem o estigma de analfabetos. Essa designação Ihes é aferida porque lhes foram negados o direito e a garantia do acesso à cultura letrada que possibilitaria participação ativa no mundo do trabalho, na política e na cultura. A educação nesta perspectiva precisa ser dotada de qualidade, não só atendendo as competências formativas básicas, mas também ultrapassando-as e possibilitando o aprender a aprender, a resolução de problemas cotidianos, o pensamento crítico- reflexivo, o lidar e responder aos atuais desafios da educação e da sociedade no que diz respeito a uma formação integral e humanística.

Nesta perspectiva, Capucho (2012, p. 25) afirma que muito é preciso ser superado com relação a "[...] interculturalidade, empregabilidade, sobrevivência, economia solidária, sustentabilidade socioambiental, democracia econômica e cultura da paz [...]". Para ele, a sociedade brasileira não rompeu "[...] com a lógica da negação dos direitos educativos de jovens e adultos (as)" (CAPUCHO, 2012, p. 25).

Estar inserido no processo de alfabetização é uma das possibilidades de crescimento de oportunidades para a inserção social e abertura de novas portas 
para construção de saberes mais avançados e superiores. Para tanto a educação de qualidade é central em qualquer sociedade e deve estar voltada para o desenvolvimento da consciência cidadã coletiva na tentativa do ensino ir além do ler,

escrever e contar. É preciso o desenvolvimento do pensamento crítico e criativo para emancipação política, social e laboral.

\section{PACTO PELA EDUCAÇÃO DE JOVENS E ADULTOS}

Segundo Gadotti e Romão (2006, p.120), só é possível pensar em erradicação do analfabetismo e elevação do nível de escolarização da população, se o sistema educacional, como um todo orgânico, desempenhar com qualidade sua tarefa independente de idade e classe social dos participantes do sistema educacional. É igualmente importante que os horizontes norteadores do atendimento desta demanda sejam a construção da cidadania e da consciência dos direitos e deveres para com o outro e com a sociedade. Há de ser considerado o envelhecimento da população, a rápida internacionalização da economia a nível mundial, a necessidade de se ter competitividade em todos os setores econômicos e a constante qualificação e requalificação dos jovens, adultos e idosos para possibilitar este salto qualitativo e a manutenção no mundo produtivo. A sociedade que pretende aumentar os anos de trabalho requeridos para aposentadoria não pode deixar de se preocupar com essa questão ao pensar quem educada, por que educa, para que educa e quais as circunstancias sociais e políticas.

Parte dos Jovens, Adultos e Idosos considerados alfabetizados, são, em verdade, analfabetos funcionais e constituem um número significativo. Esses são fundamentalmente trabalhadores- em condição de subemprego ou desempregados, submetidos a dificuldade de mobilidade urbana, alternância de turnos de trabalho, cansaço físico e psicológico. Quando frequentam a escola noturna após a jornada de trabalho diurno, não têm tempo de ir a casa antes da escola e já chegam às aulas com fome e cansados, o que prejudica manter a atenção e dedicarem-se ao que acontece na sala de aula. 
A diversidade é grande entre os participantes, é comum se sentirem acanhados ou inferiores aos professores e demais educadores que precisam de sensibilidade para criar um clima de igualdade e de acatamento das diferenças. Por isso, as palavras de Amorim (2012, p. 73) podem ser aplicadas ao clima em sala de aula com muita precisão. Ele afirma que:

Quando as pessoas participam de um diálogo franco e aberto, conseguem estabelecer um grau de relevância nas conversas e promovem o surgimento de atitudes positivas. Consequentemente diminui a distância na comunicação e na participação entre as pessoas, elimina certas hierarquias que são prejudiciais ao exercício didático em sala de aula, efetiva as ações educacionais, fazendo com que haja objetividade e dinamismo nos processos didáticos (AMORIM, 2012, p. 73).

É requerido considerar a diversidade presente nas salas de aula especialmente no turno noturno. Os participantes diferem nas experiencias vividas, nas idades, que variam, geralmente, entre de 15 a 80 anos ou mais em alguns casos. Há de se considerar também neste contexto o perfil socioeconômico, étnico, gênero, regionalidade, participação. Sendo assim as políticas publicadas pensadas para esta modalidade de ensino devem considerar todos estes fatores.

Gadotti e Romão (2006, p.122) chamam a atenção para relação da EJA com trabalho:

A EJA das camadas populares tem de, necessariamente, assumir como princípio ordenador, o mundo do trabalho. Nele, há que se considerar duas vertentes: a do questionamento das relações que engendram a sociedade e a da instrumentalização para exercer a atividade laboral. Tanto quanto possível, a educação básica de jovens e adultos deverá correlacionar essas duas vertentes ao mesmo tempo em que se desenvolve o domínio de um conhecimento crítico para questionar a realidade e transformá-la.

Moacir Gadotti lembra sempre a possibilidade de enfrentamento do Analfabetismo com a formação do "Pacto Nacional pela alfabetização de jovens e adultos". Esse Pacto poderá mobilizar União, Estados, Municípios, sociedade civil, movimentos sociais, ONGs, voluntários; estabelecer parcerias com programas de alfabetização de jovens, adultos e idosos, num esforço conjunto para pôr fim ao analfabetismo. Para Gadotti, esta poderá ser uma marca fundamental de um "Brasil sem miséria". O 
analfabetismo é fator, produto e produtor da miséria de um povo e da falta de responsabilidade da classe dos governantes e decisores da educação. Corrupção e desvio de verbas destinadas à educação, à merenda escolar, à formação de professores, à compra de material escolar, ao transporte escolar, são promotores da reprovação e evasão de estudantes e professores que não encontram as condições requeridas para a qualidade da educação.

\section{CONSIDERAÇÕES FINAIS}

A partir de 1932 com o Manifesto dos Pioneiros da Educação Nova, os movimentos em prol da alfabetização no Brasil se tornaram mais contundente, embora ainda haja um analfabetismo que gira em torno de $8 \%$ na população de 15 anos e mais. Gadotti (2014, p.14) ensina ser requerida:

[...] uma política nacional de Educação de Jovens e Adultos (EJA); uma política de Estado, e não apenas programas transitórios e conjunturais de governo. É inconcebível querer alcançar o desenvolvimento educacional dos países da OCDE sem enfrentar o desafio do analfabetismo brasileiro. Naqueles países, o analfabetismo adulto é residual (em torno de 1\%). Aqui o analfabetismo é estrutural (em torno de 10\%). No Brasil, neste momento, o que precisamos é de uma política afirmativa em defesa da EJA - como foi feito com a política de cotas nas universidades envolvendo a sociedade num grande pacto pela alfabetização de adultos. Ela deve se constituir numa "ação afirmativa".

Paulo Freire afirma que nesse empreendimento são requeridas ações "afetivas e efetivas" com características libertadoras e para tanto os aspectos políticos e emancipatórios são conjuntos essenciais dos processos de alfabetização. $O$ afeto e a empatia com o qual se ensina é parte constituinte da aprendizagem. A relevância política do que é ensinado também é capital para a leitura e compreensão do contexto socioeconômico e cultural como um todo.

As reflexões em torno das questões sócio educacionais nos levam a acreditar que numa sociedade pautada no ideário de justiça e consolidação dos direitos humanos, o investimento no ser humano constitui o centro dos planejamentos educacionais. $O$ respeito, a solidariedade e tolerância são valores principais trabalhados no contexto 
das aprendizagens. Discutir direitos humanos básicos levaria a prática do exercício e provimento dos mesmos, os quais teriam que ser acessíveis a todos e com qualidade compatível ao século XXI: educação, saúde, segurança, moradia, alimento, lazer, saneamento incluindo água, energia, esgoto. Essa sociedade é possível se as políticas sociais forem postas em prática diferente do que acontece hoje. Para existir a sociedade ideal é preciso a existência do homem ideal e da mulher ideal preocupados com a emancipação de todos.

Gestores e professores devem dialogar com seus estudantes. Suas orientações e postura devem enfatizar Educação em Direitos Humanos com enfoque interdisciplinar. Convém que as políticas públicas existentes reflitam a formação integral dos sujeitos, capacitando-os para o exercício pleno da cidadania e para o trabalho digno. Essas políticas precisam estar voltadas para as especificidades e características desses estudantes.

Parafraseando César Coll (1987): tão importante quanto o que se ensina e se aprende é como se ensina e como se aprende. Devemos quebrar o paradigma que a escola é um local onde só se transmite conteúdo; na escola é possível construir novos conteúdos e posturas políticas; a instituição educacional é responsável por transformar e construir uma nova sociedade mais solidária e humana, além de preparar cognitivamente seus alunos. A verdadeira escola assume a postura crítica perante a sociedade visando melhorá-la.

Neste contexto emerge a necessidade de uma Educação de Jovens e Adultos com vistas a emancipação e a participação social dos sujeitos envolvidos. Além de a educação ocupar-se das habilidades cognitivas e sociais de modo e capacitar os sujeitos para processar informações, suscitar discussões e posicionar-se crítica e criativamente, precisa prepará-los para o exercício consciente da cidadania e a busca de direitos já assegurados e os não assegurados ainda, como a alfabetização de qualidade e a educação para todos durante toda a vida. A alfabetização requerida vai além, muito além do ler, escrever e contar. Ela construir um mundo mais socialmente justo e igualitário com relação às oportunidades necessárias para cada 
um seguir seu rumo e afirmar-se socialmente. Paulo Freire afirmava que ninguém ensina ninguém, aluno e professor aprendem conjuntamente mediante o diálogo e a interação das trocas de saberes. Esse processo é continuo e dura toda a vida, enquanto há vida há aprendizagem.

\section{REFERÊNCIAS}

AMORIM, Antônio. Políticas Públicas em educação, tecnologia e gestão do trabalho docente. Salvador: EDUNEB, 2012.

ANTUNES, Ângela; BRANDÃO, Carlos Rodrigues. Apresentação Uma data para lembrar, um sonho a retomar. In: GADOTTI, Moacir. Por uma política nacional de Educação popular de jovens e adultos. São Paulo: Moderna: Fundação Santillana, 2014, p. 5-8.

CAPUCHO, Vera. Educação de jovens e adultos: prática pedagógica e fortalecimento da cidadania. São Paulo: Cortez,2012. (Coleção educação em direitos humanos; v.3).

COLL, Cesar. Psicologia e Currículo. Barcelona: Laia, Cadernos de Pedagogia. 1987.

FREIRE, Paulo. Educação como prática da liberdade. Rio de Janeiro: Editora Paz e Terra, 2005. 158p.

FREITAS, Katia Siqueira de. Gestão da educação: a formação em serviço como estratégia de melhoria da qualidade do desenvolvimento escolar. In: CUNHA, Maria Couto. Gestão municipal nos municípios :entraves e perspectivas. Salvador: EDUFBA, 2009.pp 166-198.

FREITAS, Katia Siqueira de. Algumas considerações sobre a política de educação de jovens e adultos e a qualidade da educação. In: SILVA, Maria Monteiro; COSTA, Graça Santos; LIMA, Isabel Maria Sampaio Oliveira (Orgs.). Diálogos sobre educação em direitos humanos e formação de jovens e adultos. Salvador: EDUFBA, 2016. p. 161-173.

GALVÃO, Ana Maria de Oliveira; DI PIERRO, Maria Clara. Preconceito contra o analfabeto. São Paulo: Cortez, 2007- (Preconceitos v. 2).

GADOTTI, Moacir e ROMÃO, José. Educação de Jovens e Adultos: Teoria, prática e proposta. São Paulo: Cortez: Instituto Paulo Freire, 2006.

GADOTTI, Moacir. Por uma Política Nacional de Educação Popular de Jovens e de Adultos. São Paulo: Ed. Moderna, 2014. 
GOFFMAN, Irving. Estigma: notas sobre a manipulação da identidade deteriorada. Rio de Janeiro. LTC Quarta edição, 2004.

TORRES, Rosa Maria. Educação para Todos: a tarefa por fazer. Porto Alegre: ARTMED Editora, 2001. 